2 Research Square

\title{
Study of Fitch Rating`s Response to Covid-19 by Logical Analysis of Data
}

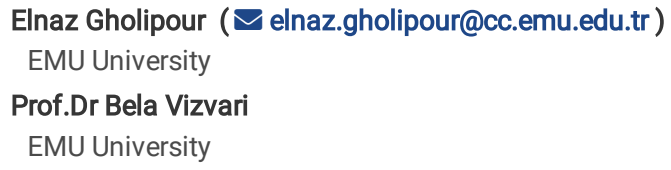




\section{Abstract}

Credit ratings, represent the creditworthiness of countries and financial organizations that nowadays due to the corona virus crisis hit the world is being threatened to be downgraded. This study uses Logical Analysis of Data to analyze the Fitch rating agency response to Covid-19. Three varied parts of variables, composed of the significant economic and social factors, pandemic -related variables and pre-credit rating (2019) are under survey. The time interval of the study is 2019-2020. The output of the research in the form of the decision trees shows the selected patterns of each newly published Fitch rating in July of 2020. The consequences of the research in training and test sets by $100 \%$ and $80 \%$ matched cases, respectively shed light on the robust results of explored patterns. Surveying on Fitch

sresponse $\in$ thisspanshowedt $\hat{p}$ and emic - relatedvariab $\leq$ smostlyhaveanimpacton" $B$ "s and theywere $\neg$ sign if icant $\in$ " $\in$ vestment $\nabla$ es $s$ credit rating may be a strong factor to forecast next ratings just in normal state of affairs, nevertheless, selected well-built economic and social factors described the hidden structure of Fitch Agency in the optimum way during pandemic also.

\section{Introduction}

Sovereign debt is the amount of money, that a government has borrowed typically issued as bonds, then when a country is unable to get a low interest rate from lenders to pay its bills, a sovereign debt crisis occurs. Credit rating agencies construct the creditworthiness of financial institutions and countries by classification of them into the particular rating system. Thomas Friedman (1995) published a report about a two-superpower world that is the U.S and Credit Rating Agencies, first can vanish a country by leveling it with bombs and second destroy a country by downgrading its bounds. Therefore, economic prosperity, public debt and stable policy of a country, form the rating system of the agencies.

Fitch credit rating relevant to issuers is an ability of an entity to meet financial obligations. Credit ratings are used by investors as indicators of the likelihood of receiving the money owed to them on which they invested. However, in current time, the crippling influence of the coronavirus crisis has pushed governments and corporate finances towards debt soaring. Marc Jones [1] had a report in business news about the statistics of downgrades that have been already made by three biggest credit rating agencies so far this year. Further to backwards of a pandemic, downgrades might be a considerable threat to economies and doubtful questions about up-coming ratings.

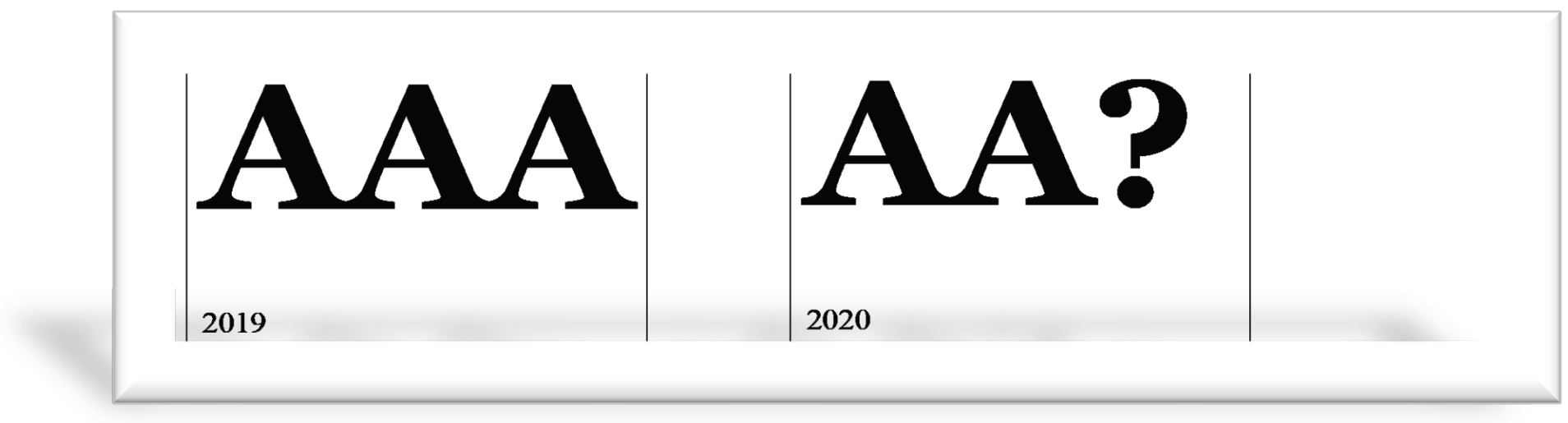

Credit ratings are categorized into two main groups: investment grade and speculative grade.

AAA to BBBM (BBB-) is involved into "Investment grade" whereas "BBP" to "D" is called "High Yield" or "speculative grade". "AAA" ratings denote the lowest expectation of default risk. They are assigned to the strong capacity for payment of financial commitments. In contrast, from the view point of Credit agencies, below BBBM is not worth consideration. Meanwhile, without the acceptable rating, how countries will be successful to access in the financial market to deal with heavy debts that is a main way to fall off the amount of bills and survive from governmental debt After Covid-19. In crisis times Downgrades may indeed have a severe impression on sovereigns and corporate finances.

\subsection{Impact of the Pandemic}

As rating agencies evaluate the COVID-19 effect, they assess what the long-term impact of the coronavirus crisis will be. The rating agencies need to determine whether the consequences of the short-term credit rating conduct to long-term, or is a different rate structure required to express risks to investors that are connected to temporary ratings? [2]. Looking at the Fitch Rating response since the coronavirus crisis broke out, it seems that high yield or junk rated countries have been affected more, forcing them deeper into junk zone (Table 1) that it has been proved in our study also. From investment grade, the most notable country was Canada, which downgraded from AAA to AAP (AA+) by Fitch on June 24. To better understand the negative effect of the pandemic on credit ratings, we listed up-graded, kept-stable and down-graded countries by each credit rating agency below (Figure 1). 


\begin{tabular}{|c|c|c|c|c|c|}
\hline Country & 2019 & 2020 & Country & 2019 & 2020 \\
\hline Cape Verde & B & $\overline{B M}$ & Morocco & BBBM & $\mathrm{BBP}$ \\
\hline Cameroon & $\overline{\mathrm{BM}}$ & $\mathrm{B}$ & Sri Lanka & $\bar{B}$ & $\overline{\mathrm{CCC}}$ \\
\hline Canada & AAA & AAP & Tunisia & BP & B \\
\hline Chile & $\mathrm{A}$ & $\overline{\mathrm{AM}}$ & Armenia & $\overline{\mathrm{BBM}}$ & $\overline{\mathrm{BP}}$ \\
\hline Colombia & $\overline{B B B}$ & $\overline{\mathrm{BBBM}}$ & Bahrain & $\overline{\mathrm{BBM}}$ & $\overline{B P}$ \\
\hline Gabon & $\mathrm{B}$ & $\overline{\mathrm{CCC}}$ & Bolivia & $\overline{\mathrm{BP}}$ & B \\
\hline Guatemala & BBB & BBM & Costa Rica & $\mathrm{BP}$ & $\mathrm{B}$ \\
\hline Mexico & BBB & BBBM & Nigeria & $\mathrm{BP}$ & $\mathrm{B}$ \\
\hline
\end{tabular}

Table 1: some down-graded countries by Fitch Rating Agency in 2020

We were not likely to be a witness of a lot of immediate downgrades during the first waves of the pandemic, but the reality was a little bit different. Moreover, this is a question if more countries ' credit ratings will be downgraded during this crisis in the coming months.

There was an deep observation on the economic and social factors with strong and robust attributes for rating system which nowadays hit by pandemic, what extent of pre-explored factors have been affected by the crisis and whether is any other effective element to be added to the structure of rating to be able to rate the countries in the optimum way during pandemic, that will likely continue as a main driver of credit risk. Consequently, finding out the modified patterns will be the main contribution of this research.

\subsection{Economic and Social variables during pandemic}

The world policy to the deadly and costly Coronavirus Crisis made governments to have a high debt-to-GDP ratios. To pay for many of these programs, countries will require to have access to financial markets. This phenomenon shed light on the response of the credit rating agencies to the pandemic, how the countries and financial institutions will be rated. The negative outlook of sovereign downgrades at the outset of the pandemic has slowed-moved significantly since June and will continue to decelerate in the months ahead. Sovereign credits experience considerable stresses following of the negative view points about downgrades that may reach to below the historical average [3]. Accordingly, it is certain to follow the trend of the main variables of pre-explored patterns of the Fitch Rating system [4] to analyze its response to COVID-19.

GDP per Capita (\$) \& GDP Growth Rate (annual \%);

GDP is the overall value of goods and services for last use, produced by inhabitant producers in an economy. GDP per capita and GDP per capita annual growth rate are extensively utilized by economists to recognize the health of an economy [5]. According to current reports, on average, GDP per capita is intended to decline in 2020 in comparison with 2019 internationally. Global statistics of GDP growth compared to previous years as follows;

$2020 * \quad-3.03 \%$

$2019 \quad 2.9 \%$

$2018 \quad 3.58 \%$

Whereas, Fitch Rating expected from GDP growth to fall to $1.3 \%$ in 2020 from $2.9 \%$ in 2019 , lockdown affected the expectation dramatically to decrease to $-3.03 \%$.

$\underline{\text { Inflation, }}$ Consumer Prices (annual \%);

The pandemic and associated lockdown features might have an effect on supply chain and demand for particular products and following their prices. During the crisis, uncertainty can lead to a risk of de-anchoring wherein short-term prices can change long -term expectations [6]. Some do not believe inflation because many industries as hotels, gasoline or airfares pulled the index down. Actually, cheap, but the unwanted product basket does not show inflation. The Wall Street Journal reported that inflation is somewhere for the materials you really want to buy [7]. In spite of some beliefs about not being particular inflation during pandemic because of falling-off prices and discounts in most industries, the demand for certain crisis-related products will be increasing.

\section{Unemployment Rate (\%);}

The Coronavirus disease crossed every territory and industries across the world, and lockdown changed workforce policy of nearly all institutions and companies [8]. Static says, the unemployment rate hit 5.42\% in 2020 and remained 0.02 percentage points higher than 2019. Young or low-educated workers, women and part-time labors endured more proportion of the unemployment rate.

2020 * $\quad 5.42 \%$

$2019 \quad 5.4 \%$

$2018 \quad 5.39 \%$ 
Overall, more people in the world prefer to live in urban than in rural areas since 2010. In 2020, 56.2 percent of the world population is urban, while, fast distribution of COVID-19 occurs in the crowded environments. Then, as social key factor was investigated among other variables also.

Government Debt (debt to \% of GDP);

The COVID-19 shutdown, pushed emergency expenditure to societies that it caused government debt to balloon. Then, logically, governments have two ways to come back to pre-COVID debt level. They may cut spending or increasing taxes. In the current situation, it seems to be difficult to cut COVID-19-related costs, similarly, the second way will be concluded by hurting consumer spending, more bankruptcies and limited investments. Accordingly, as a tolerable mean, access to financial markets to diminish the amount of government debts is a necessity. Indeed, being rated in investment grade, by credit rating agencies during crisis, will be essential for countries.

\section{Gross Saving (\% of GDP);}

The historic jump in saving in 2020 was a definite product of the COVID-19 pandemic response [9]. The household saving rate recorded its highest annual increase in the first season of 2020. In the short-term, it is natural. Since with the lockdown, the options for consumptions declined. Moreover, uncertainty for work and financial issues makes household saving, rising up in a pandemic to warranty themselves in facing with any unforeseen events. Spending may occur when consumption is safe.

\section{$\underline{\text { Total COVID-19`s Infected Cases; }}$}

This element shows the whole confirmed coronavirus infected persons in each country till the end of July 2020 that WHO organization reported.

\section{Total Deaths of COVID-19.}

The number of persons who died since COVID-19 hit them in every country till the end of July 2020.

\section{Credit Ratings of 2019 by Fitch $(100-0)$;}

Benmelech [10] studied to observe which variable might be mostly tied to spending, then Country`s pre-crisis sovereign credit rating as a strong determinant came out. Therefore, we valued this factor as the third part of variables based on Fitch rating measurement (Table 2).

\begin{tabular}{|c|c|}
\hline Value & Credit Rating \\
\hline 100 & AAA \\
\hline 95 & AAP \\
\hline 90 & AA \\
\hline 85 & AAM \\
\hline 80 & AP \\
\hline 75 & A \\
\hline 70 & AM \\
\hline 65 & BBBP \\
\hline 60 & BBB \\
\hline 55 & BBBM \\
\hline 50 & BBP \\
\hline 45 & BB \\
\hline 40 & BBM \\
\hline 35 & BP \\
\hline 30 & B \\
\hline 25 & BM \\
\hline
\end{tabular}

Table 2: Credit Rating Values of Fitch

\section{Methodolgy}

Logical Analysis of Data (LAD) as a data mining method based on optimization and Boolean logic utilized here creates objective and transparent outputs by using the minimum number of the variables which describe the rating system of Fitch in an optimum way [11- 12]. The minimum set of cut-points is called the optimum solution of the specific rating class. Countries of the training and test sets are assigned to 1 or 0 depends on their 2020 `s ratings. The sets composed of 60 and 33 countries respectively.

Three varied parts of variables have been studied in this research;

1. Economic and social variables; GDP per Capita, GDP Growth Rate, Inflation, Unemployment Rate, Urban Population, Government Debt, Gross Saving.

2. Covid-19 related variables; Total COVID-19`s Infected Cases, Total Deaths of COVID-19.

3. Fitch Credit Ratings of countries for 2019

To run LAD program, the highest permitted degree for a pattern was 3 . The prevalence was at least $60 \%$. The homogeneity was claimed to be $100 \%$. The data set of the research gathered from Worldbank, WHO Organization and Wikipedia covering the period 2019-2020. LAD is applicable only if the numerical data are "translated" into Boolean measures. It constructs cut-points which means separating values between different classes. Cut-points created by LAD form a decision tree. If a country satisfies the cut-point separating "AAA" countries from others, then it is classified as "AAA". Apart from that, if it satisfies the Loading [MathJax]/jax/output/CommonHTML/fonts/TeX/fontdata.js hen it is categorized as "AAP" country (Figure 2). 


\section{Results}

\subsection{Application of LAD to explore Fitch response to COVID-19}

The following decision tree specifies the patterns and specific attributes for each country in the set.

\{credit rating of 2019>=97.5\} AND $\{$ GDP per capita $>=50943.5\}=$ "AAA"

\{credit rating of 2019>=92.5\} AND $\{$ GDP per capita $>=46156\}=$ "AAP"

\{credit rating of 2019>=87.5\} AND \{gross saving >=16.5, GDP per capita >=40370.5\} = "AA"

\{credit rating of 2019>=82.5, government debt<=119.05, GDP per capita $>=21621.5\}=$ "AAM"

$\{$ credit rating of 2019>=77.5, government debt $<=119.05$, GDP per capita $>=10062.5\}=" A P "$

$\{$ GDP per capita $>=17902.5$, unemployment rate<=9.9, GDP growth $>=0.5\}$ OR \{urban population $>=60.45$, GDP per capita $>=10062.5$, credit rating of $2019>=77.5\}$ $=" \mathrm{~A} "$

\{inflation $<=2.93091$, credit rating of 2019>=67.5\} ="AM"

\{credit rating of 2019>=62.5, unemployment rate<=16.6, GDP per capita $>=6705\}=" B B B P "$

$\{$ unemployment rate<=10.9, credit rating of 2019 $>=57.5$, GDP growth $>=0.5\}$ OR \{urban population $>=65.2$, inflation<=2.4, credit rating of 2019 $>=57.5\}=" B B B "$

$\{$ total infected cases of COVID-19>=1189, credit rating of 2019>=52.5, inflation $>=0.35\}$ OR \{total deaths of COVID-19>=17.908, credit rating of 2019>=52.5, inflation $>=0.35\}=$ "BBBM"

\{credit rating of 2019>=47.5, total infected cases of COVID-19>=1189, unemployment rate $<16.6\}$ OR

$\{$ credit rating of $2019>=47.5$, total deaths of COVID-19>=17.9, unemployment rate $<16.6\}=" B B P "$

\{credit rating of 2019 $>=42.5$, inflation $<=11.05$, unemployment rate $>=2.65\}$ OR $\{$ GDP per capita $>=3544$, government debt $<=60.5$, credit rating of $2019>=47.5\}$ ="BB"

\{total infected cases of COVID-19>=400, GDP per capita $>=1960.5$, credit rating of 2019>=37.5\} OR

$\{$ total deaths of COVID-19>=6, GDP per capita $>=1960.5$, credit rating of 2019>=37.5 $\}=" B B M "$

$\{$ total infected cases of COVID-19>=400, credit rating of 2019>=32.5, gross saving $>=8.5\}$ OR $\{$ credit rating of $2019>=32.5$, inflation $<=5.05$, gross saving $<=34.5\}$ $=$ "BP"

$\{$ urban population $>=21.85$, inflation $>=0.15$, credit rating of 2019 $>=32.5\}$ OR \{government debt<=66.65, gross saving $<=36.5\}=" B "$

$\{$ GDP per capita $>=7534.5$, credit rating of $2019>=32.5\}$ OR \{gross saving $<=36.5$, urban population $>=21.85\}=" B M "$

The application of the decision trees is easy. Only the values of the patterns in question should be available. The user only compares the measures with the values of the given cut-points.

\subsection{Overview of variables based on A and B classes;}

Out of the economic and social factors, GDP per capita, Government debt, GDP growth, Inflation and gross saving have frequently been out in " $A$ " classes from "AAA" to "AM". Certainly, GDP per capita is shining among them as the most important factor for " $A$ "- related ratings. None of "A" classes were affected by pandemic factors in currently announced countries ' credit ratings by Fitch. By contrast, "Credit rating of 2019", was observed in whole ratings from "AAA" to "BM". The considerable point of this part is about COVID-19 relevant variables that came out in "speculative grades" from "BBBM" to "BP". The impressive observation is, as much as we go down through ratings, value of COVID-19 attributes, Cut-points, falls down. It shows that coronavirus crises threat pre-lowrated countries to be downgraded more by the Fitch Rating system during the pandemic. This phenomenon was shown in Table1.

\section{Discussion}

The study examined Fitch Rating response to COVID-19 through 10 variables. The main contribution of the research is adding coronavirus factors to the study to analyze whether newly announced credit ratings affected by pandemic.

The out-come of LAD in the form of a decision tree describe whole 16 rating levels completely at $100 \%$ matched-result of training set that was verified nearly $80 \%$ of matched out-put in the test set. To compare $20 \%$ of mis-rated countries with our result, there are some countries which are downgraded or upgraded as follows;

Upgraded by Fitch: Germany, Kuwait and Saudi Arabia have been rated "AAA", "AA", "A" in 2020 that in our result, they got rated "AAP", "AAM", "AM" in order. Loading [MathJax]/jax/output/CommonHTML/fonts/TeX/fontdata.js 
Downgraded by Fitch: Fitch Rating reported ranking of Bahrain, Cyprus, Portugal and San Marino in B-related classes as "BP", "BBBM", "BBB" and "BBP" respectively in 2020 that they all rated as " $A$ " rating in our result. In comparison with our consequence, Fitch Agency downgraded Bolivia, Costa Rica and Ecuador to one low rating class from "BP" to "B" and from "B" to "BM".

To conclude, even in coronavirus crisis, still economic and social variables are well-defined factors to describe the credit rating system optimally. However, the historical credit rating of countries is a main factor within all rating levels. The pandemic impact is traced in new credit ratings as its negative effect on economic factors. COVID-19 variables became apparent among the selected patterns to describe high yields (lower rating levels).

\section{Conclusion}

The estimation of high debt has been pushed up by virus to the world`s nations, is a threat to downgrade ratings. Certainly, the users of the credit rating agencies want to keep their money somewhere safe. Safety may be a principle than returns following the worldwide crisis and Covid-19 shut down. Therefore, the present study tried to analyze the hidden structure of the Fitch Rating agency during pandemic. By application of LAD, the explored rating system was summarized in the form of the decision tree. It can even be used to estimate the ratings of otherwise unrated countries in 2020.

Out of the three parts of variables, "Pre-crisis credit rating" may forecast next ratings effectively, however, in the case of any crisis, as COVID-19, it cannot be only reliable factor where all sections of economy and social life are closed to be crushed by this virus.

To sum up the contributions of the present study, "pre credit rating" beside significant economic and social factors will structure well-organized patterns to describe different levels of Ratings optimally even in a pandemic. COVID-19 variables got out in "B" class ratings that they already placed in speculative grades. Conforming to the result of this research, COVID-19 related variables had not impressive effect on Fitch credit rating evaluation on JULY 2020. It may be studied hereafter to analyze its consequences precisely. Also, we reached that Fitch agency might intend to downgrade the countries which are in "speculative grades" or "high yields" more.

\section{References}

- Online document

Jones,M.:How the coronavirus is crushing credit ratings.Reuters.https://www.reuters.com/article/

us-health-coronavirus-ratings-graphic-idUSKCN24U18Y. 2020

\section{- Journal article}

Borries, S.: Rating agencies continue to analyze and re-evaluate COVID-19 impact. Working Paper. https://www.bakertilly.com/insights/rating-agenciescontinue-to-analyze-and-re-evaluate. (2020).

- Online document

Fitch Ratings group.: The Ratings Process, How Fitch Assigns Credit Ratings. Special report. https://www.fitchratings.com/products/ratings-process. 2019

- Article by DOI

Gholipour, E., et al.: Reconstruction Rating Model of Sovereign Debt by Logical Analysis of Data. arXiv preprint arXiv:2011.14112. (2020)

- Journal article

König, M. and A. Winkler.: COVID-19 and Economic Growth: Does Good Government Performance Pay Off?. Intereconomics 55(4): 224-231. (2020).

- Online document

Ebrahimy, E., et al.: The impact of COVID-19 on inflation: potential drivers and dynamics. IMF Research. 2020

- Online document 
Pittis, D.: Inflation numbers really are being distorted by COVID-19 spending; new research shows.CBC.https://www.cbc.ca/news/business/inflation-spendingcpi-covid-19-1.5765625. 2020

- Online document

CRS members.: Unemployment rates during the COVID-19 pandemic in brief. Congressional Research Service. R46554. 2020

- Online document

Garcia, J.: Savings and COVID-19: how far will Europe`s saving fever go?. CaixaBank research. https://www.caixabankresearch.com/en/economicsmarkets/activity-growth/savings-and-covid-19-how-far-will-europes-saving-fever-go. . 2020

- Journal article

Benmelech, E.: How credit ratings are shaping governments` response to COVID-19. Kellogg school of management at Northwestern University.https://insight.kellogg.northwestern.edu /article /credit-ratings-shaping-governments-responses-covid-19. (2020).

- Journal article

Kogan, A., M. A. Lejeune.:Combinatorial methods for constructing credit risk ratings. Handbook of quantitative finance and risk management, Springer: $639-$ 664. (2010).

- Journal article

Hammer, P. L., et al.: A logical analysis of banks' financial strength ratings. Expert Systems with Applications 39(9): 7808-7821. (2012).

- Online document

Corona-virus dataset.: Covid-19 dashboard Situation by Country, Territory \& Area. World Health Organization. https://covid19.who.int/table. . 2020

- Online document

Dataset of the Economic \& Social variables.: World bank open data. WorldBank. https://data.worldbank.org/. 2019

- Online document

Dataset online resource.: List of countries by credit rating”. Wikipedia. https://en.wikipedia.org/wiki/List_of_countries_by_credit_rating. 2020

- Online document

Fitch Ratings groups “Coronavirus sovereign rating shock subsides, prolonged stress ahead.

FitchWire.https://www.fitchratings.com/research/sovereigns/coronavirus-sovereignrating-shock

-subsides -prolonged-stress-ahead-25-08-2020. 2020

\section{Figures}




\section{0 up-dated credit ratings by three agencies}
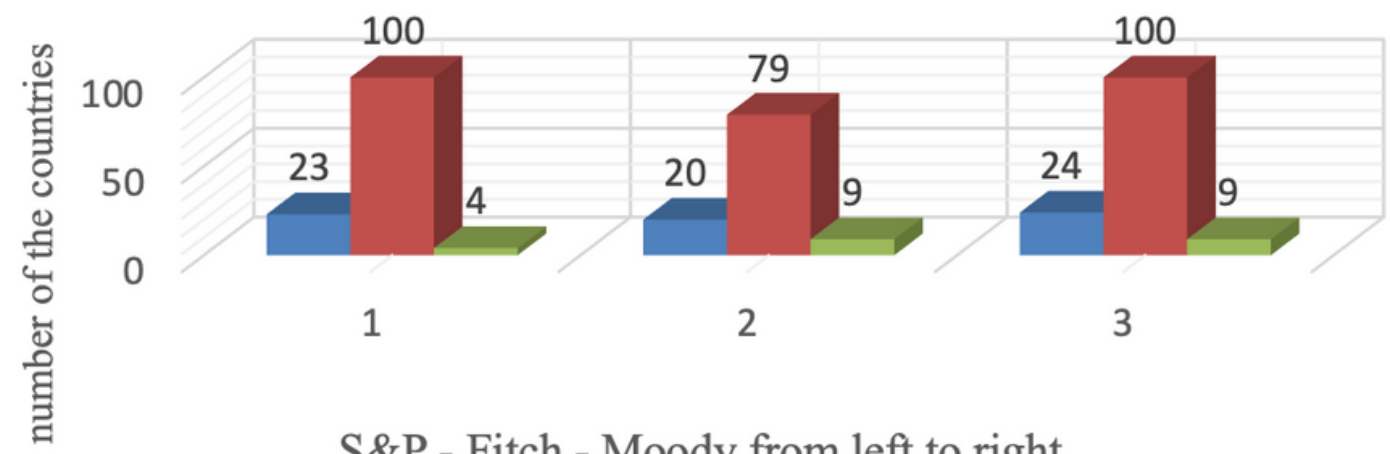

S\&P - Fitch - Moody from left to right

Down-graded $\quad$ Kept-stable $\quad$ Up- graded

Figure 1

The number of the countries for three status by different CRAs

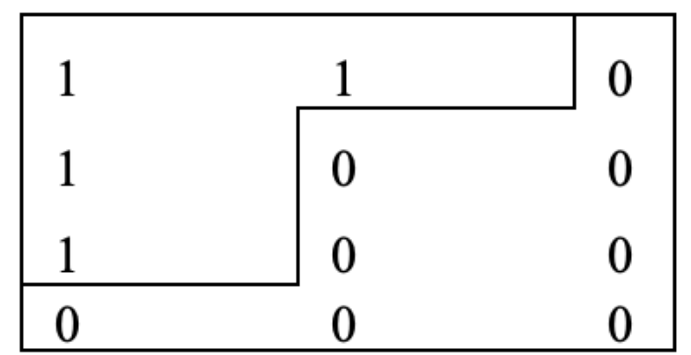

\begin{tabular}{|ll|l|}
\hline \multirow{2}{*}{ AAA } & AAA & 0 \\
AAA & 0 & 0 \\
AAA & 0 & 0 \\
\hline 0 & 0 & 0 \\
\hline
\end{tabular}

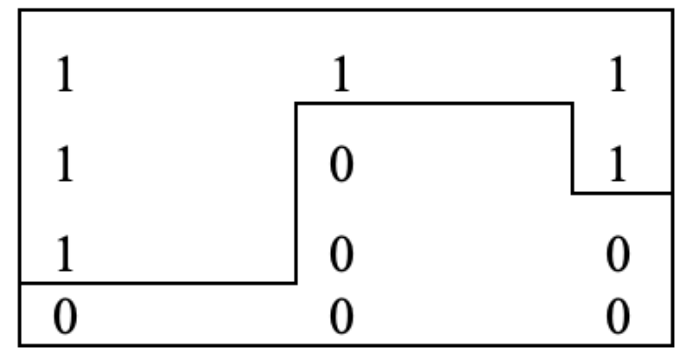

\begin{tabular}{|c|c|c|}
\hline $\mathrm{AAA}$ & $\mathrm{AAA}$ & AAP \\
\hline $\mathrm{AAA}$ & 0 & AAP \\
\hline AAA & 0 & 0 \\
\hline 0 & 0 & 0 \\
\hline
\end{tabular}

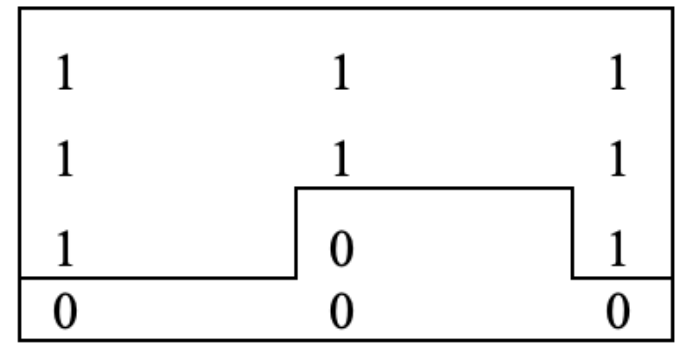

\begin{tabular}{|lll|}
\hline AAA & AAA & AAP \\
AAA & AA & AAP \\
AAA & 0 & AA \\
\hline 0 & 0 & 0 \\
\hline
\end{tabular}

Figure 2

selected countries as an output of LAD for different ratings 